\title{
ACUTE ENCEPHALOPATHY AND ARSENOTHERAPY OF SYPHILIS \\ BY
}

\author{
J. SYDNEY MCCANN \\ Hon. Venereologist, Ulster Hospital for Children and Women, Belfast; Acting Assistant Physician to the \\ Venereal Diseases Department, Royal Victoria Hospital, Belfast
}

Acute hæmorrhagic encephalitis or encephalopathy is, perhaps, one of the most dreaded of complications which can occur during arsenotherapy of syphilis. Before the introduction of intensive arsenotherapy by Chargin and others (1935), the incidence of this condition was almost negligible ; according to Harrison (1939), only 8 cases were reported from 800,000 injections during the war of 1914-18. Since the popularization of intensive arsenotherapy during the world war 1939-45, however, the incidence of encephalopathy has increased considerably. Its incidence varies according to different workers: thus Young and Gordon (1944) report 5 fatalities from acute encephalopathy following about 10,000 injections at an East African Centre, the drug used being neoarsphenamine, $0.6 \mathrm{~g}$. twice weekly, in addition to 2 weekly injections of bismuth metal of $0.1 \mathrm{~g}$. each. Lydon (1944) reports that 5 out of 53 patients developed the condition during treatment by a short-term intensive course of mapharside; one of his patients died. Pillsbury and others (1944) state that the reaction of encephalopathy did not occur frequently during intensive arsenotherapy by a modified 20-day treatment. Lloyd Jones and Maitland (1945) report 3 cases out of a total of 241 (?) patients treated by a modified course of intensive arsenotherapy.

According to McDonagh (1920), the condition develops some 48 to 72 hours after the second or third injection. Pillsbury and others, quoting U.S.A. Army circular letter No. 138 on intensive therapy for early syphilis, say that it is characterized by " mild to severe mental confusion, headaches, fever, convulsive seizures, and in some cases coma. Spinal fluid sometimes shows marked increase in protein." The treatment most generally adopted is venesection, lumbar puncture, intravenous hypertonic glucose, and the administration of adrenaline or benzedrine, but the results of treatment have varied (McDonagh, 1920 ; Young and Gordon 1944; Lydon, 1944). The use of thiosulphate, intravenously has also been advocated (Sheppe, 1930).

Lydon (1944) brings out several points of interest and importance which do not appear to have been noted by other workers. In his series of cases he observed that the primary signs of encephalopathy occurred in the mental sphere, either as a sudden explosive onset of acute apprehension and fear, or as a general slowing of cerebration. The resemblance of these mental changes to those of the two types of alcoholism led to a tentative suggestion that perhaps a similar pathological condition was present and that the condition might be avoided or improved upon the exhibition of vitamin $\mathbf{B}_{1}$. Alcoholism is suggested as a predisposing factor. Upon this hypothesis vitamin $\mathbf{B}_{1}$ was administered in the later cases of the series quoted, with apparently marked benefit. The following case is of interest in the light of Lydon's observations.

\section{Case History}

The patient was a male, aged 24 years, who was referred for examination on Sept. 22, 1944, for a possible syphilitic infection. He was undergoing treatment for co-existent scabies, and gave a history of exposure to infection in the previous March. He stated that in March, 1944, following exposure, he had developed a urethral discharge which had been treated with sulphathiazole. He had had a penile swelling since the following May or June and was using calamine lotion locally. He was suffering from malaise and was sleeping poorly due to the irritation caused by the scabies. He admitted to fairly heavy alcohol consumption up to 3 or 4 weeks before examination.

On examination there was penile swelling, marginal ulceration and induration of the prepuce, marked enlargement of the inguinal glands, and superficial ulceration of the right tonsil with redness of both tonsillar regions. There was an 
indefinite secondary rash confined chiefly to the lower abdomen, though it was difficult to be certain about this on account of the superimposed scabies.

Due to the local treatment, $T$. pallidum was not definitely demonstrated on the first examination but was found on the patient's next reporting on Sept. 25. Treatment was begun on the same day, when $0.04 \mathrm{~g}$. mapharside in sodium thiosulphate solution was administered intravenously. On Sept. 27 and 29 and on Oct. 2, 0.06 g. mapharside were given, together with $0: 1 \mathrm{~g}$. bismuth on each day. The patient lived in the country and returned home after each treatment. Several days after the fourth injection his doctor telephoned to say that the patient was confined to bed with influenza and was unable to come for further treatment meantime ; his doctor was not alarmed about his condition. On Oct. 7 a further message reported that the patient was still ill but his doctor was still not unduly alarmed; but on Oct. 9 his condition was reported to be much worse and he was now delirious. Personal difficulties had delayed his earlier hospitalization, but it was obviously impossible to treat him by directions by telephone ; admission to hospital was urged, and he was admitted the same evening.

A more coherent history of events was now obtained. He had gone to bed on account of a " cold" following his last injection; by the next day his temperature had risen to $103^{\circ} \mathrm{F}$. He remained in bed, and his high temperature continued until Oct. 6, when it fell to $99^{\circ} \mathrm{F}$., when his condition improved somewhat; but on Oct. 8 he developed convulsive fits and became comatose 5 or 6 hours later. The coma lasted until the early hours of the following morning. He had been lethargic and had taken very little food or liquids since his return home on the day of his last injection.

On admission to hospital, he was in a very excitable state and was shouting and struggling. He was quite unconscious of his surroundings and unable to recognize his mother. He appeared to be very apprehensive of all that was happening and made violent efforts to get out of bed, being restrained with considerable difficulty-so much so that clinical examination was extremely difficult and unsatisfactory. There was a divergent strabismus of the left eye, marked neck rigidity, and a positive Kernig's sign. He was incontinent.

Further examination or interference were impossible for several hours, when a lumbar puncture was performed with some difficulty. About $20 \mathrm{c.cm}$. of clear cerebrospinal fluid was withdrawn and was reported on as follows : protein $120 \mathrm{mg}$. per $100 \mathrm{c.cm}$. ; chlorides $700 \mathrm{mg}$. per $100 \mathrm{c.cm}$. ; globulin increased; cells 20 lymphocytes per c.mm.
Further treatment consisted in the intravenous administration of $50 \mathrm{c.cm}$. of $30 \%$ dextrose and $20 \mathrm{c.cm}$. calcium gluconate. On Oct. 10, by nasal feed at 4 a.m. he was given 2 pints of glucose and sedatives. Large quantities of fluids were given. Fluids were forced. The patient was still very noisy and difficult to restrain in spite of sedatives. On Oct. 11 he was drowsy and quieter. When wakened for drinks, his eyes and face were quite expressionless.

By Oct. 12 he was somewhat brighter and was attempting to speak, but articulation was difficult ; his face was still expressionless. He recognized his mother. On Oct. 13 he was more normal and was able to talk and take food. He asked to be changed to another ward with other patients, as he said there was a tall, dark man behind the curtain who kept looking at him during the night. (There was no curtain in the ward.) On Oct. 14 he had a good night. He was bright and talkative during the day and was taking food normally.

Subsequent progress was uneventful. A lumbar puncture on Oct. 21 showed protein, $40 \mathrm{mg}$. per 100 c.cm.; globulin negative; chlorides, 670 mg. per 100 c.cm. ; cells, 10 lymphocytes per c.mm.

Most authorities agree that further exhibition of arsenicals is absolutely contraindicated after a crisis of the type described. Unfortunately, penicillin was not then available and we were faced with the alternatives of either continuing treatment with bismuth or of risking a further cautious dose of an arsenical preparation. Here was a man, 24 years of age, who had had inadequate treatment for secondary syphilis, and who was now faced with the alternatives either of inadequate treatment of a very serious condition, with all the dire possibilities consequent thereon, or of the risk of further arsenotherapy. It was considered that, taking a long view, a further cautious dose of mapharside should be tried.

His general condition was now much better than it had been at the beginning of treatment, and he had shown no evidence of further mental reactions. On Oct. 23 an injection of $0.02 \mathrm{~g}$. of mapharside in high dilution and containing $0.45 \mathrm{~g}$. thiosulphate was given very slowly intravenously. About 2 hours after the injection the patient's face became flushed, his eyes became slightly injected, and he developed a headache which lasted until the next morning. On Oct. 24 it was decided to start injections of vitamin $B_{1}$, and daily thereafter until his discharge from hospital on Nov. 16, 1944, he was given an intramuscular injection of $5 \mathrm{mg}$. of thiamine hydrochloride.

On Oct. 30 a further injection of $0.02 \mathrm{~g}$. of mapharside was given, with the same precautions as before. About 4 hours after the injection, the patient's face became flushed, his eyes injected, 
and his body warm, but the reaction was not only much less than before, but it lasted only 4 to 5 hours. There was no headache. On Nov. 5 he was given $0.03 \mathrm{~g}$. of mapharside as before, and this time he had a slight feeling of warmth which lasted for a few minutes only. On Nov. 13, after $0.04 \mathrm{~g}$. of mapharside given with the same precautions, he had no reaction whatsoever.

Between Nov. 27 and Dec. 20, 1944, after his discharge from hospital, the patient had 4 injections of $0.04 \mathrm{~g}$. mapharisde without further untoward reaction. During the following 12 months he had 2 further courses of treatment, each consisting of 10 weekly injections of $0.04 \mathrm{~g}$. mapharside and $0.1 \mathrm{~g}$. bismuth. During the first of these courses thiamine hydrochloride was given daily intramuscularly, and during subsequent treatment oral vitamin B therapy was administered. There was no further reaction of import during treatment, and his blood Wassermann and Dreyer reactions have remained negative for some time. $\mathrm{He}$ is still under periodic observation.

\section{Discussion}

It is difficult to draw conclusions from a single case, but when the condition is comparatively rare the observed reactions in individual cases become of considerable importance. The case described would appear to bear out at least some of the conclusions reached by Lydon (1944). Unfortunately, circumstances prevented personal observation of the symptoms during the onset of the condition, but from what was learned subsequently the onset seems to have been rather of the lethargic type as described by Lydon. Most workers are agreed that the first 3 or 4 injections during arsenotherapy should be given over a period of some 10 to 14 days, and the treatment in this case was not out of harmony with recognized practice. The clinical findings and the result of lumbar puncture were like those described in other cases of similar type. Lydon (1944) points out that Kernig's sign was not a feature of his cases, and suggests that, in the single case he noted, the sign was probably one of nuchal rigidity. This may have been so in the patient described in this paper.

The chief point of interest in the case described is the response to treatment following encephalopathy. It was an admitted risk to recommence arsenotherapy, but the circumstances governing the decision to do so have already been discussed. In retrospect it would seem that perhaps an even smaller trial dose of the drug should have been administered. The reaction to the first injection of mapharside after encephalopathy, and the rapidly decreasing reactions following the second and subsequent injections on the exhibition of vitamin $B_{1}$, would seem to bear out Lydon's theory about the importance of this vitamin in the prevention of arsenical encephalopathy.

The advent of penicillin for the treatment of syphilis brought with it high hopes that arsenical encephalopathy would be a thing of the past. It is now, however, becoming more generally realized that the best therapeutic results in the treatment of syphilis with penicillin are to be obtained, not with penicillin alone, but by combining penicillin with the older established methods of treatment. Some workers (e.g. Pillsbury, 1946) advocate a short intensive course of arsenotherapy with penicillin. There is thus still the possibility of the occurrence of encephalopathy, and the use of vitamin $B_{1}$ in its prevention or treatment is worth further investigation. Alcoholism may also play a part in the causation of the condition.

1 am indebted to Surgeon Commander Hugo Hall, R.N.V.R., Director, V.D. Clinic, Royal Victoria Hospital, Belfast, for criticism and advice, and to Dr. F. Kane, Medical Superintendent, Purdysburn Fever Hospital, Belfast, for help during the early days of the patient's illness.

\section{REFERENCES}

Chargin, L., Leifer, W., and Hyman, H. T. (1935). J. Amer. med. Ass., 104, 878.

Harrison, L. W. (1939). Brit. Encyc. med. Pract., 11, 605. London.

Lloyd Jones, T. R., and Maitland, F. Gordon (1945). Ibid., 21, 166.

Lydon, F. L. (1944). Brit. J. vener. Dis., 20, 87. McDonagh, J. E. R. (1920). "Venereal Diseases." Heinemann, London. P. 235.

Pillsbury, D. M., Courville, C. J., Crede, R. H., Myers, J. D., and Wise, C. R. (1944). Brit. J. vener. Dis., $20,154$.

Pillsbury, D. M. (1946). Ibid., 22, 90.

Sheppe, W. M. (1930). W. Va. med. J., 26, 732.

Young, W. A. and Gordon, S. (1944). Brit. J. vener. Dis., $20,34$. 